\title{
Fizikten Metafiziğe: Ön-Sokratik Sokrates ve İkinci Yolculluğu
}

\section{From Physics to Metaphysics: Pre-Socratic Socrates and his Second Voyage}

\author{
Muharrem Hafiz ${ }^{1}$ (D)
}

'(Doç. Dr.), İstanbul Üniversitesi, İlahiyat Fakültesi, İstanbul, Türkiye

\section{ORCID: M.F. 0000-0001-5262-1413}

Sorumlu yazar/Corresponding author: Muharrem Hafız

İstanbul Üniversitesi, İlahiyat Fakültesi, İstanbul, Türkiye

E-mail/E-posta: muharremhafiz@outlook.com

Başvuru/Submitted: 31.10 .2021 Revizyon Talebi/Revision Requested: 27.12.2021

Son Revizyon/Last Revision Received: 28.12.2021

Kabul/Accepted: 02.01.2022

Citation/Atıf: Hafız, Muharrem. "Fizikten Metafiziğe: Ön-Sokratik Sokrates ve İkinci Yolculuğu." Felsefe Arkivi-Archives of Philosophy, 55 (2021): 17-33. https://doi.org/10.26650/arcp.1017032

\section{öz}

Phaidon diyaloğunda Sokrates, dostlarılla birlikte ruhun ölümsüzlüğü üzerine konuştuktan sonra, Kebes'in itirazı üzerine ona doğru dönerek hakikati arayış yolculuğunda kendi hayat hikayesi ve tecrübesini paylaşır. Kebes'e göre ruhun bu dünyadan önce var olması, sonrasında da varlığını sürdüreceği anlamına gelmez. Ayrıca ona göre bedenden bedene dolaşan ruh, bu dolaşımla yok olup gider ve bu nedenle ölümsüzlük diye bir şeyden bahsedilemez. Bu bağlamda Sokrates, ruhun ölümsüzlüğüne ilişkin Kebes'in itirazını ele almanın zorluğuna işaret eder ve bu meselede oluş ve bozuluşun nedeninin araştırılması gerektiğini ifade eder. Bu noktada Sokrates gençlik yıllarında kendisinin de "neden" arayışı içerisinde olduğundan ve Anaksagoras başta olmak üzere doğa araştırmacılarından etkilendiğinden bahseder. Öte yandan Sokrates doğal neden arayışındaki umutlarının da boşa çıktığını belirtir. Bu umut yitiminden sonra Sokrates 'logoi'a sığınma' olarak belirttiği "ikinci yolculuğa" (deuteros plous) çıkar. Oluş dünyasına tabi her şeyin kendisine göre gerçekleştiği ilkesel nedeni doğanın içinde arayan düşünürlerin çelişkilerini fark eden genç Sokrates'in, fiziki dünyadan metafiziğe doğru seyreden yolculuğu bu yazının konusunu oluşturmaktadır. Ayrıca bu yazının amacı, ruhun ölümsüzlüğü gibi bir meselede, Sokrates'in kendi hayat hikayesini paylaşmasının gerekçesini araştırmak ve buradan hareketle Kebes'in itirazına yönelik Sokratik arayışın izlerini sürmektir.

Anahtar Kelimeler: Phaidon, Ön-Sokratik, Sokrates, Ruh, Ölümsüzlük

\section{ABSTRACT}

In the dialogue of Phaedo, Socrates talks about the immortality of the soul with his friends and shares his life story and experience in his journey of seeking the truth after Cebes' objection to immortality. According to Cebes, the soul's existence prior to this world does not imply that it will continue to exist beyond it. Furthermore, the spirit that circulates from one body to another perishes as a result of this circulation; hence, there is no such thing as immortality. Socrates emphasizes the difficulties of dealing with Cebes' objection to the immortality of the soul in this setting and adds that the reason of becoming and corruption in this subject should be investigated. 
At this point, Socrates explains how, in his youth, he was likewise looking for "cause," and how nature researchers, particularly Anaxagoras, impacted him. Whereas, Socrates also states that his glorious hope was quickly snatched away from him. After this loss of hope, Socrates takes on the "second voyage" (deuteros plous), which he refers to as "taking refuge in the logoi." The subject of this article is the second voyage of young Socrates who perceived the contradictions of the thinkers who look for the principal cause in nature and the Socratic quest that progresses from a physical journey to metaphysics in a way. In addition, this article aims to investigate the reason why Socrates shared his own life story in terms of the causal explanation of this world on a subject such as the immortality of the soul and to follow the traces of the Socratic search from this point of view.

Keywords: Phaedo, Pre-Socratic, Socrates, Soul, Immortality

\section{EXTENDED ABSTRACT}

Unlike the Socratic argument of disproof or refutation (elenchus), a very different method emerges in the part of Phaedo (95b-107a). Against Cebes' objection, Socrates outlines how, as a young man, he was interested in the causal explanation of becoming-world, but he also explains why he was dissatisfied with the traditional physical (scientific) explanations of the time. Thus, Socrates provides a summary of his intellectual autobiography by discussing his youth interest in the approach of nature researchers. In this respect, Socrates' answer to the objection of Cebes is presented concerning Socrates' confrontation with Pre-Socratic philosophy.

Socrates states that he took the "second voyage" (99d: deuteros plous), because of his disappointment with the teleological explanations that reduce "cause" to purely physical things. However, he also states that before this journey, he was interested in the science (sophia) known as natural research (peri physeos historian) in his youth and it seemed very important for him to know the cause of everything. In fact, when we look at the things that Socrates was interested in and focused on, we find ourselves in what we now call Pre-Socratic philosophy. Despite the stark distinctions in the history of philosophy, the young Socrates appears to have a Pre-Socratic phase in this regard.

Socrates acknowledges being significantly impacted by Anaxagoras' nous idea when seeking for the cause of everything (97c). Socrates believes he can explain the true cause of things and hopes to understand the perfection of the universe from Anaxagoras (97d). Although the idea that the reason for everything is reason satisfied Socrates at first, he realizes that the "nous" of Anaxagoras is far from explaining the real and unchangeable cause in the universe as he deepens his research. On the other hand, Socrates signifies his first journey as resulting in great disappointment and loss of hope. Therefore, Socrates reveals not the simple negation of a PreSocratic natural science in this part of the dialogue, but the failure of the 'Pre-Socratic Socrates' himself from his own experience of life. Moreover, as Socrates progresses in his research, he sees that Anaxagoras' cosmic nous (97c) has physical extensions and is incapable of understanding the "perfect", which in a way can be seen as a metaphysical principle. It should be noted that Socrates made this comment in response to Cebes, who was having trouble overcoming natural causation and reasoning in a study of the soul and its immortality. 
The second voyage in Socrates' search for the cause is the new path defined as taking refuge in logoi. It does not seem possible to explain the logos or logoi in Socrates with Aristotelian logic. First of all, Socrates' second journey is related to his distrust and disappointment with teleological explanations that reduce the cause to the physical things. In this respect, the "second journey" is the second road that Socrates took after the inadequacies of theoretical physics. Furthermore, Socrates attempts to overcome the tension that Cebes perceives between the indestructibility of the soul and its immortality by directing his attention to his "knowledge of self" gained from his own life experience. In other words, Cebes' claim that "the indivisibility of the soul does not in principle guarantee one's immortality" finds its place in Socrates' dialectic of life. In this sense, Socrates expresses in his own life experience to realize that the soul is immortal based on truth and the necessity for experiencing the practice of death and spiritual purification to acquire immortality in this world.

Unlike the Pre-Socratics, Socrates states that he should search for his relationship with external objects in the terms of his logoi and hypothesize (hypothesis) the existence of ideas in themselves. It is obvious that the ideas in Socrates/Plato cannot be considered as a "scientific hypothesis" (assumption) with its modern content. Plato probably thinks that the Pre-Socratics regarded their logoi as an object of knowledge with definite and absolute content, thus deprived of the art of discourse (logon tekhne) which could lead the addressee to reach correct knowledge based on truth. However, the Pre-Socratics do not seek to advance beyond their logoi and remain stuck in them. As a result, Pre-Socratics are unable to provide accurate explanations (logoi) for their arguments. As a result, Socrates underwent a "Pre-Socratic" stage, during which he searched for causes inside nature itself. This shows us that the distinction between the Pre-Socratic and the Socratic stage presented in the history of philosophy is not very sharp and that there is a dialectical transition between the natural and the transcendent metaphysical search for Socrates. 


\section{Giriş}

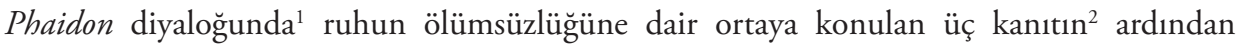
Sokrates, bu konuda şüpheleri hala devam eden Kebes'in itirazını çürütmeye çalışır. Kebes, ruhların bedenden bedene dolaştığını, bu dolaşımla yok olup gideceğini ve bu nedenle de ölümsüzlükten bahsedilemeyeceğini savunur. Böylece bedenden bedene dolaşan ruh, çeşitli hastalık ve sıkıntılar içinde yaşar; kendisine ölüm geldiğinde de yok olup gider (95c-d). ${ }^{3}$ Bunun üzerine Sokrates uzun bir süre sessiz kalır, kendi kendine düşünür ve şunları söyler:

Kebes, incelediğimiz mesele hiç de basit değil. Çünkü oluşun ve bozuluşun nedenini (aitia) baştan aşağı araştırmak gerekir. Önce bu konudaki deneyimimi anlatayım sana; sonra istersen söylediklerimden sana yararlı görünenleri, söyleyeceklerini desteklemek için kullanırsın" (95e-96a, italik bana ait).

Diğer kanıtlarda görmeye alışık olduğumuz Sokratik élenkhos'tan ${ }^{4}$ farklı olarak diyaloğun bu bölümünde (95b-107a) çok farklı bir yöntem karşımıza çıkar. Kebes’in itirazına karşı Sokrates, gençlik yıllarında doğa bilimine ilgi duyduğunu ve özellikle Anaksagoras’tan etkilendiğini belirtmesine rağmen, aynı zamanda o günün bilimsel açıklamalarından neden tatmin olmadığını da anlatır. Sokrates daha sonra eşyanın hakikatini (99e: ton onton ten alétheian) dışsal olanda değil de, logoi itibariyle kendisinde araması gerektiğini fark ederek idealar üzerinden ruhun ölümsüzlüğünü kanıtlamak ister. Bu konuşmasında Sokrates, doğa biliminden ideaları keşfine kadar da bazı aşamalardan geçtiğinden bahseder. Bunlar 1) Sokrates’in, gerçek nedeni, doğa bilimlerinde aradığı ve Anaksagoras' in peşinden gidip onun "nous" kavramından etkilendiği, 11) eşyanın hakikatini dişsal olanda değil, kendi içinde (logoi da) ${ }^{5}$ bulduğu, 111) değişmez ideaları keşfedip ona uygun hipotez oluşturarak ruhun ölümsüzlüğünü kanıtlamaya çalıştığı aşamalarıdır.

Sokrates'in -deyim yerindeyse- entelektüel otobiyografisinin sunulduğu bu bölüm, onun gençlik yıllarında doğa bilimine beslediği ilgi üzerine yoğunlaşır. Bu açıdan Phaidon diyaloğunun genel teması olan ruhun ölümsüzlüğü gibi ruhun ölümsüzlüğüne yönelik itirazlar da, Sokrates’in, Ön-Sokratik (Pre-Socratic) felsefeyle ilişkisi ve hesaplaşması sorunundan bağımsız değildir. Ancak bu bölümde Sokrates'in, ruhun ölümsüzlüğünü kanıtlama tarzı kendi deneyimi üzerinden sunulduğundan, bunu sıradan bir Ön-Sokratik anlatım ya da aktarım olarak değil, "Ön-Sokratik Sokrates” in bilgiyi ve gerçekliği sorgulaması üzerinden anlamak daha doğru bir yaklaşımdır. Bu nedenle ben doğa araştırmacılarının (96a-97c) ve özellikle Anaksagoras'ın kendisi üzerindeki etkisi (97b-99b) nedeniyle Sokrates'in erken ya da gençlik dönemini "Ön-Sokratik Sokrates" olarak nitelendiriyorum.

1 Bu makalede -gerekli gördüğüm yerlerde bazı değişikliklere gitmek kaydıyla- Nazile Kalaycı'nın Phaidon çevirisini kullandım. Ayrıca bu diyalogdaki Yunanca terimler için Harold North Fowler'ın Eski Yunanca aslıyla birlikte basılan İngilizce çevirisine başvurdum.

2 Oluşun döngüselliği (70c-72e), hatırlama (72e-77b) ve benzerlik kanıtları (78b-84b).

3 Metin içerisinde verilen Stephanus numaraları aksi belirtilmedikçe Phaidon diyaloğuna referansla kullanılacaktır.

4 Herhangi bir konuda soru cevap tarzında yapılan ve muhakeme dayalı soruşturma.

5 "Logoi"un ardından gelen kesme işaretinden sonraki ekler, sözcüğün (logoy olarak) okunuşuna göre düzenlenmiştir. 


\section{1. Ön-Sokratik Sokrates ve Birinci Yolculuğu}

Sokrates'in "gerçek neden" arayışını kendi hayat hikayesi üzerinden bir "gemi yolculuğu" metaforuyla anlatması, Simmias'ın diyalogdaki önceki konuşmasında sunduğu benzetmeyle bağlantılıdır. ${ }^{6}$ Buna göre Kebes'ten önce Simmias, ruhun ölümsüzlüğüne ilişkin kendi itirazını dile getirmeden önce şunları söyler:

İtirazımı sana söylemek istiyorum, sonra da dediklerini neden kabul etmediğini Kebes sana anlatsın. Bu tür konulara dair kesin bilgi edinmenin bu yaşamda ya imkansız ya da çok zor olduğunu düşünüyorum, belki sen de böyle düşünüyorsun. Bununla birlikte bu konuda söylenmiş olanları her yönüyle sınamadan ve büsbütün yorgun düşünceye kadar araştırmadan bırakmak kesinlikle iradesiz bir insana özgüdür. Bu konularda şunları yapmak gerekir: Ya onların ne olduğunu öğrenmek ya da keşfetmek. Bunlar imkansızsa, en azından insanoğlunun dile getireceği en iyi ve en zor çürütülebilir görüşü almalı, onun üzerine tıpkı bir sala biner gibi binip tehlikelere karşı yelken açarak geçirmeli yaşamı. Böylece sağlam bir taşıt ya da tanrısal bir söz bulunmadığında yolculuğun daha güvenilir ve daha tehlikesiz yapılması olanaklı olacaktır (85c-d).

İlerleyen satırlarda görüleceği gibi Sokrates, Simmias'ın bu benzetmesini, ona derin anlamlar yükleyerek ruhun ölümsüzlüğü hakkında Kebes’e karşı kullanır. Böylece, nedeni, salt fiziksel şeylere indirgeyen teleolojik açıklamalardan duyduğu hayal kırıklı̆̆ından ötürü Sokrates, kendisinin ifadesiyle "ikinci yolculuğa" (99d: deuteros plous) çıktığını dile getirir. Ancak bu yolculuğundan önce Sokrates'in gençlik yıllarında doğa araştırmaları (peri physeos historian) olarak bilinen ilme (sophia) duyduğu meraktan ve şeylerin nedenini doğal bir süreç içindeki arayışından bahsetmek gerekir.

Diyalogda doğrudan geçmemesine rağmen ikincisine referansla buna "birinci yolculuk" (prōtos plous) diyebiliriz. Aslında Sokrates'in merak duyup araştırmak için yöneldiği konulara baktığımızda, "Ön-Sokratik" olarak nitelendireceğimiz bir alanla karşı karşıya kalıyoruz. Bu açıdan felsefe tarihinde Ön-Sokratikler ile Sokrates arasında varsayılan keskin ayrımın aksine, genç Sokrates'in Ön-Sokratik bir döneminin olduğu söylenebilir. Ayrıca Sokrates’in, ruhun ölümsüzlüğü gibi bir meseleye fiziksel dünyanın oluş ve bozuluşundan çıkamadan bakamayan Kebes'e, kendi entelektüel otobiyografisini açması da sıradan değildir. Bu konuya yeniden döneceğim. Ancak öncelikle Sokrates'in, Ön-Sokratik doğa biliminden ne umduğu ve ne bulduğu konusu üzerinde durmam gerekiyor. Sokrates doğa bilimine yönelirken cevap aradığ soruları şöyle sıralıyor:

Şu türden konuları araştırarak dolanıp duruyordum: Canlıların oluşmasını sağlayan, kimilerinin söylediği gibi, sıcak ile soğuğun sağladığı çürüme midir?

Düşünmemizi sağlayan kan mı, hava mı, ateş midir? Yoksa işitme, görme, koklama

6 Donald L. Ross, “The Deuteros Plous, Simmias' Speech, and Socrates' Answer to Cebes in Plato’s Phaedo”, Hermes, 110/1 (1982), 19-25. 
duyularını sağlayan, onlardan hafızayı ve sanıyı oluşturan, hafıza ve sanı belli bir dinginliğe ulaştığında bunlardan bilgiyi meydana getiren şey beyin midir? Sonra bütün bunların yokoluşlarını yeniden ele aldım; gökteki ve yeryüzündeki olayları inceledim. (96b-c).

Öte yandan Sokrates bu araştırmanın kendisini körleştirdiği ve daha önce bildiği pek çok şeyi unutturduğunu, dolayısıyla "birinci yolculuk" olarak isimlendirebileceğimiz bu ilk yolun, büyük bir hayal kırıklığı ve umut yitimiyle sonuçlandığını ifade eder (96c). Sokrates bunun açıklamasını şu şekilde sunar:

Önceleri şunun herkes için açık olduğunu sanırdım: İnsanın büyüyüp gelişmesinin ardındaki neden, yemek içmektir. Besinlerden çıkan etler etlere, kemikler kemiklere ve öteki parçalar da aynı şekilde kendileri uygun olanlara eklenir. Böylece önce küçük olan kütle sonra büyür; küçük insan da aynı şekilde büyük insan olur (96cd).

Sokrates bu yöntem tarzıyla herhangi bir şeyin gerçekten neden meydana geldiğini, varlığını ve yokluğunu izah edemediğini, hatta bu konularda kendisini dahi ikna edemediğini dile getirir. Bunun ardından Sokrates her şeyin nedenini ararken Anaksagoras'ın "nous” kavramından fazlasıyla etkilendiğinden bahseder (97c). Anaksagoras'tan, evrendeki her şey için geçerli olan en iyi ve en mükemmeli öğrenmeyi uman Sokrates böylece her şeyin gerçek nedenini açıklayabileceğini düşünür (97d). Her şeyin nedeninin akıl (nous) olduğu fikri başlarda Sokrates’i tatmin etse de, araştırmalarını derinleştirdikçe Anaksagoras'ın nous'unun da evrendeki gerçek ve değişmez nedeni açıklamaktan uzak olduğunu fark eder. Böylece Sokrates "bu koca umudun da yok olup gittiğini” (98b) ve neden araştırmasını salt fiziksel açıklamalardan hareketle yapmanın ruhunu körelttiğini belirtir. Dolayısıyla diyaloğun bu kısmında Sokrates’in Ön-Sokratik bir doğa biliminin basit bir tarzda olumsuzlamasını değil, bizatihi kendi yaşam tecrübesinden hareketle 'Ön-Sokratik Sokrates’in başarısızlığını gözler önüne serer. Dahası, Sokrates araştırmasında ilerledikçe Anaksagoras'in 'kozmik nous'unun (97c) fiziksel uzantılı olduğunu ve bir bakıma metafizik ilke olarak görülebilecek "en iyi” nin anlaşılmasında yetersiz kaldığını görür. Bunun yanısıra Sokrates Anaksagoras'ın gerçekte aklı hiç kullanmadığını ve şeyleri düzene sokan bir neden de ileri sürmediğini savunmaktadır (98b). Zira Sokrates'e göre Anaksagoras'ın şahsında Ön-Sokratik doğa bilimcileri olarak nitelendirebileceğimiz bu kişiler, en iyi ve mükemmel olanın, "her şeyi bir arada tutan ve onları birbirine bağlayan bir şey olması gerektiğini akıllarına getirmezler" (99c).

Kebes'in itirazına yanıt olarak Sokrates'in, Ön-Sokratik doğa bilimiyle hesaplaşmasından bahsetmesi ilginçtir. Ayrıca Sokrates’ in, bu açıklamayı, ruha dair bir araştırmada doğal nedenselliği ve muhakeme mantığını aşmakta zorlanan Kebes'e hitaben yaptığı unutulmamalıdır. Ruhun ölümsüzlüğüne karşı Kebes'in itirazına yeniden bakıldığında, bu kişinin, "ruh” gibi doğaüstü ve metafizik bir meseleye, oluşun döngüselliği ve fiziksel dünyanın nedenselliğinden başka türlü bakamadığı görülecektir. Zaten Sokrates de kendi yaşam deneyimini paylaşarak bu meselelere 
salt fizik ve doğa araştırmaları perspektifinden bakmanın kişinin ruhunu körleştireceğinden bahsederek, Kebes'in dikkatini muhakeme ötesi bir araştırma yöntemine doğru çeker. Bana öyle geliyor ki, bu pasajın en can alıcı noktalarından biri de, ruhun ölümsüzlüğüne dair Sokrates' in "kendi" entelektüel otobiyografisi üzerinden bir savunu yapmış olmasıdır. Dolayısıyla diyaloğun bu kısmında, "ben”in kendi dönüşümünün izleri takip edilmeden ve öz farkındalık kazanılmadan, ruhun ölümsüzlüğünün idrak edilmesinin zorluğuna işaret edilmektedir. Zira diyaloğun başlarında bu durum şu şekilde ifade edilmektedir: "Saf olmayanların saf olanları kavraması mümkün değildir” (67b).

Sokrates' in birinciyolculuğundaki hayal kırıklığını Kebes' in itirazıylabirliktedüşündüğümüzde dikkatlerden kaçmaması gereken bir diğer nokta da şudur: Kebes ruhun bedene göre dağılmaz, bozulmaz ve basit olduğunu kabul edip, ölümsüzlüğe karşı içinde şüphe beslemektedir. Bu açıdan baktığımızda da Sokrates'in Kebes'e bu şekilde yanıt vermesi, muhatabın şüphesiyle ilgilidir. Bu nedenle Sokrates, Kebes'in itirazını, önceki kanıtlamalardan farklı olarak muhakeme açısından akla daha uygun bir argüman talebi olarak değil, muhatabına bir şeyin gösterilmesi açısından ele alır. Dolayısıyla Kebes’in zorluğu, üzerinde durulan mevzunun, muhakemeye (dianoia) aşkın görüsel bir tecrübeyle (noesis) ilişkili olduğunu bir türlü kavrayamamasıdır. Bu nedenle Sokrates'in amacı, ruhun ölümsüz olduğunu bir yaşam tecrübesi olarak muhatabına göstermektir. Başka bir deyişle ruhun da içinde olduğu düşünülen bir dünyada her şeyin akışta olduğu şüphesi bir şekilde izale edilmelidir. ${ }^{7}$

Sokrates'in Ön-Sokratik birinci yolculuğundan ikinciye nasıl açıldığı konusuna geçmeden önce bir hususun daha altını çizmekte fayda var. O da Kebes’in, önceki kanıtlamalardan hareketle ruhun dağılmaz/basit (anolethros) olduğunu kabul edip ölümsüzlüğü kabul etmemesi noktasında yaşadığı gerilimdir. Aslında Sokrates'in Kebes'e yönelik yanıtındaki tecrübî boyut derinlemesine analiz edildiğinde görülecektir ki, ruhun dağılmaz ve basit oluşu, ilkesel olarak birinin ölümsüzlüğe kavuşacağını garanti etmez. Başka bir deyişle Sokrates’in birinci ve ikinci yolculuğundaki anlatısını paylaşması, ruhun ölümsüzlüğünün salt muhakeme konusu olmadığı, ölüm pratiği ve ruhun arınması yoluyla kazanılacak bir tecrübeyi gerektirdiği hususuyla doğrudan bağlantılıdır. Ancak diyaloğun genelinden anlaşıldığı kadarıyla Kebes, muhakeme mantığını aşıp görüsel tecrübe boyutuna geçememektedir. Bu noktada ben, Sokrates'in otobiyografik anlatımından hareketle ruhun ölümsüzlügünün, muhakeme yoluyla elde edilen düşünsel birikimin, kendilik (auto) idraki yoluyla aşılması konusuyla bağlantılı olduğunu düşünüyorum. Diyaloğun bu kısmından sonra da Sokrates Ön-Sokratik doğa biliminde kendisini umutsuzluğa sevk eden yönleri belirtir ve ikinci yolculuğundan bahsetmek sûretiyle bir bakıma muhakeme mantığını aşma noktasında kendi deneyimlerini paylaşır. Sokrates'in metafizik ideaları keşfi ve ruhun ölümsüz olduğunu kanıtladığı son argüman da (99d-107a) bu yolculukla bağlantılıdır. Böylece Sokrates eşyanın hakikatini dış dünyada değil de, bir 'ben' tecrübesi itibariyle logoìda araması gerektiğini fark ederek idealar teorisini ortaya koyar ve buradan hareketle ruhun ölümsüzlüğünü yeniden kanıtlamaya girişir.

7 Michael Pakaluk, “The Ultimate Final Argument”, The Review of Metaphysics, 63/3 (2010), 649-650. 


\title{
2. Sokrates'in İkinci Yolculuğu
}

Sokrates'in neden araştırmasındaki ikinci yolculuk logoi a sığınmak olarak tanımlanan yeni yoldur. Bunu Aristotelesçi mantıkla izah etmek pek mümkün görünmüyor. Her şeyden önce Sokrates' in ikinci yolculuğa açılması, nedeni salt fiziksel şeylere indirgeyen teleolojik açıklamalara duyduğu güvensizlik ve hayal kırıklığıyla ilgilidir. Bu yönüyle ikinci yol(culuk), teorik fiziğin yetersizlikleri sonrasında Sokrates'in çıktığı yeni yoldur. Sokrates metaforik bir anlatımla bu yolun doğasından şu şekilde bahseder:

\begin{abstract}
Varolanları ( $t a$ onta) incelemekten tam vazgeçmişken güneş tutulmasını seyredenlerin ve araştıranların başına gelen şeye uğramayayım diye dikkatli olmam gerektiğini anladım. Çünkü onun sudaki ya da buna benzer bir şeydeki görüntüsüne (eikon) bakmayan pek çok kişi gözlerini bile bozabilir. Benim düşündüğüm de böyle bir şeydi; yani nesnelere (pragmata) gözlerimle bakmanın ya da onları duyularımdan biriyle kavramaya çalışmanın, ruhumu bütünüyle körleştireceğinden korkuyordum. Söylemlere/teorilere $(\operatorname{logoi})^{8}$ sığınmak ve varolanlara ilişkin hakikati onlarda aramak gerektiğini düşündüm (99d-e).
\end{abstract}

Sokrates'in ikinci yolculuğunun, bir tehlikeye karşı korunma ihtiyacıyla başlaması önemlidir. Bu tehlike, güneş tutulmasında güneşe çıplak gözle bakmanın kişiyi kör etmesiyle karşılaştırılır. Sokrates burada güneşe ya da güneş tutulmasına doğrudan bakan bir kişi ile görünür şeylere bağlı kalan ve onları yalnızca duyularla kavramaya çalışan biri arasında benzerlik ilişkisi kurar. Her ikisi de gözü ve ruhu körleştirir/köreltir. Bu körlük kişiye önceden bildiği ya da bildiğini zannettiği şeyleri de unutturur (96c). Gerekli olan şey, eşyanın hakikatini onlarda değil, onların imgesel karşılıkları olan ben'de/logoìda aramaktır. Bu arayış da kişinin kendi özünü keşfetmesi ve bu özü keşfetmesi dolayımıyla özsel şeylerle ilişki kurabilmesini gerektirir. Kişinin cehaletinin farkına varması eşyaya dair bilginin duyularda değil, başka bir düzlemde aranması gerektiğine yönelik farkındalık ile başlar. Bu farkındalık ise ikinci yolculuğun ön koşuludur. Sokrates bu yoldaki konumunu doğrudan güneşe değil, güneşin sudaki görüntüsüne bakanların durumuna benzetmektedir. Bunlar varlığın sûretlerinin güvenli bir şekilde incelenebileceği ortamı temin eden logoi'dur.

Bu noktada Sokrates'in "logos” ya da çoğulu "logoi” ile ne kastettiğini araştırmak gerekir. Başka bir deyişle 'Ön-Sokratik Sokrates'i, birinci yolculuğun tehlikelerinden koruyan logoi nedir? $\mathrm{Bu}$ soruyu açmak için Sokrates' in benzetmesinden yararlanabiliriz. Bu benzetmede Sokrates güneşin kendisinden çok, onun yansımasına (sûretine: eikon) bakmak gerektiğinden bahseder. Aslında bu benzetme yanıltıcı olabilir. Zaten bu pasajın devamında Sokrates de bu benzetmenin çok uygun olmadığını ifade eder. Zira Devlet diyaloğunun VI. kitabında İyi (Agathon) İdeası güneşe benzetilmiş ve mağara benzetmesi bağlamında filozofun hakiki/mutlak bilgi nesnesi

8 H.N. Fowler bu terimi İngilizce’ye “conception”, Nazile Kalaycı da “düşünceler” olarak çevirir. Ancak ben, logoi un; zihinsel kavram, önerme ya da düşünceden ziyade, saf idealara nispetle ortaya atılmış açıklamalar bakımından "teoriler" olarak anlaşılması gerektiğini düşünüyorum. Bununla birlikte metin boyunca bu terimi Yunanca aslıyla kullamayı tercih ettim. 
olarak sunulmuştur. Halbuki burada güneş, duyumsanabilir varolanlara akıl gücüyle değil de, duyularla bakmanın bir benzeri olarak verilir. Ayrıca bu pasajda Sokrates iki benzetme arasındaki uygunsuzluğa da dikkatleri çekerek "varolanları logoi da araştıran kişinin, onları olgulardan çok, imgelerde araması gerektiğini” (100a) ifade etmiş ve ikinci yolculuğunda yöntem tarzının bu olduğunu açıkça beyan etmiştir. Aslında bu ifade de kafa karıştıcı gibi görünebilir. Zira Platon ontolojisinde varolan(lar) (to on/ta onta), çoğunlukla, değişmez ve sabit idealara referansla kullanılır. Halbuki tartışmanın bağlamı dikkate alındığında burada dile getirilen "varolanlar"ın, dışsal nesneler (mevcûdât) olduğu görülür. Dolayısıyla Sokrates "birinci yolculuğun” yetersizliğini görüp, eşyanın hakikatini olgularda aramaktan vazgeçer ve onları logoìda araması gerektiğini fark eder. Bu nedenle varlık ile mevcûdât arasında aracı konuma yerleştirilen logoi’a sığınmak/ başvurmak, ruhu köreltme tehlikesinden korur. Böylece Sokrates olguların dişta görünen ve tahakkuk etmiş halleriyle araştırmak yerine, eşdeğerleri veya imgesel karşılıkları (sûretleri) aracılığıyla onlar hakkında konuşmanın daha güvenli olduğunu dile getirir.

Logoi şeylerin dışta gerçekleşmiş halleriyle değil, ben'deki karşılığı itibariyle kavram, önerme, düşünce ya da teori olarak anlaşılabilir. Dolayısıyla Sokrates'e göre oluş, bozuluş ve varlık nedeni hakkında dışsal şeylerin kendileri değil, onların logoi daki karşılıklarının birer imge olarak incelenmesi gerekir.' Buradan hareketle logoi, eşyanın 'ben'deki sûretleri açısından yorumlanabilir. Benim eşyayı salt duyusal olarak bilme imkanım yok ise, bu durumda onun bendeki sûretleri ya da karşılıkları hakkında konuşabilirim. Ancak buradaki 'eikon olarak logoi' Kantçı içeriğiyle "temsil”" şeklinde anlaşılmamalıdır. Nitekim Kant açısından duyumsanabilir şeylerin bilgisi, ancak onların bendeki temsilleri üzerinden oluşturulur. Başka bir ifadeyle Kant için temsillerden bağımsız olarak şeylerin kendiliklerini ya da kendinde şeyleri (idea) bilmeme imkan yoktur. Halbuki Platon ontolojisinde logoi, ne duyumsanabilir şeylerin ne de onların hakiki varlıkları itibariyle ideaların yerine geçecek bir tarzda ikame ya da temsil olarak anlaşılabilir. Aksine bu pasajın devamında Sokrates ideaların hakiki varlığını (ousia) konuşmasına dahil eder ve mevcûdâtın varlığa olan bağlılığını, logoi aracilığıyla, onların mahiyetlerine (eide) uygun bir erişim ve katılımla kurmayı dener. Bu açıdan birinci yolculuğun ruhu köreltici yanından ziyade, logoi’a sığınan biri, varolan tek tek şeylerin hakikatine güvenli bir yolla erişebilir. ${ }^{10}$

Sokrates'in ikinci yolculuğu, teorik fiziğin yetersizliklerini gördükten sonra çıktığı ikinci yoldur. Burada doğrudan başarılamayan bir işin dolayıma sokulması söz konusudur. Zira nedensellik itibariyle eşyanın hakiki doğasına doğrudan onlara yönelerek erişilemiyorsa, bu durumda, onların ben'deki imgesel karşılıklarının incelenmesi bakımından bir tür dolayımdan bahsedilmesi gerekir. Bu bağlamda ikinci yolculukla edinilen tecrübenin, fiziksel araştırmaya göre daha değersiz ve aşağı olması icabeder. Ancak diyalogda böyle bir şey açıkça tartışılmıyor. Üstelik Sokrates bir "bilim ideali" denilebilecek tarzda "gerçek bir ilk yolculuk"tan, başka bir deyişle "hakiki bir bilimsel/teleolojik yaklaşım”dan da bahsetmiyor. Burada Sokrates'in muhatabının bakışını çevirdiği nokta, fiziksel (dışsal) olandan metafiziksel (içsel) olana doğru bir çekilmenin tecrübe itibariyle imkanıdır. Bununla birlikte diyaloğun bu bölümünde Sokrates tarafından

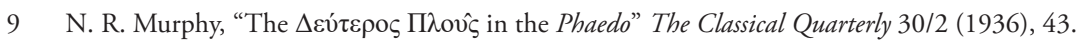

10 John Sallis, Being and Logos: Reading the Platonic Dialogues (Indianapolis: Indiana University Press, 1996), 43. 
dile getirilen mesele, basit anlamda fiziksel nesnelerden saf idealara dönme değil, en azından bu aşamada fiziksel olguları anlamak için ideal modelleri kullanmakla ilgilidir. ${ }^{11}$

Sokrates ayrıca varlığın nedenini fiziksel şeylerde arayanları "karanlıkta el yordamıyla ilerleyenlere" (99b) benzetmektedir. Mefhum-u muhalifinden hareketle nesnelerin gerçek varoluş nedenini araştırırken, aklın ve logoi un ışığına gönderme yapan Sokrates’in, Descartes'ten çok önce aklın doğal ışığını (lumen naturale) ön plana çıkardığı da iddia edilebilir. Üstelik Sokrates’in, güneşten ziyade güneşe bakanlardan bahsetmesi de önemsiz değildir. Güneş tutulmasında kişi güneşe çıplak gözle bakabilir. Yine de bu bakış, kişiyi ışığın kaynağına ulaştırmaz. Dolayısıyla Sokrates, ruhunun körelmesine karşı korunmak için logoi’a başvurur. Bu nedenle Sokrates eşyanın gerçek nedenini duyumsal olanlarda değil, akıl ve logos düzeyinde arar.

$\mathrm{Bu}$ benzetmede logoi yukarıda ifade ettiğim gibi gibi duyumsanabilir şeylere doğrudan bakmanın tehlikesine karşı, nesnelerin imgesel karşılıkları olarak sunulmaktadır. Dolayısıyla Platon ontolojisinde nesnelerin, asıllarına kıyasla sûret olarak aktarıldığı göz önünde bulundurulduğunda, Sokrates tarafindan yapılan bu açıklamada sûretten yine başka bir sûrete geçişten bahsedilmektedir. Başka bir deyişle Sokrates için logoi de fiziksel şeyler kadar sûrettir. Bu bağlamda Sokrates aslında bakışını imgeden hakiki olana değil, bir tür imgeden başka bir imgeye çevirir. ${ }^{12}$ Ancak saf idrak/görünün (noesis) konusu olan değişmez (konu bağlamı itibariyle 'ölümsüz’) idealara geçişin imkanı, oluş ve bozuluşun gerçek nedenini dış dünyada değil, logoìda aramaktır. Bu açıdan Sokrates'in logoi'dan idealara -yolculuk benzetmesinden hareketle- bir seyrinden bahsedilebilir. Dolayısıyla varolanların gerçekliğini salt oluş dünyasının olgusallığında arayan Ön-Sokratik yöntemin aksine, onları söylemlerde/teorilerde (logoi) kullanma tekniği açısından diyalogda diyalektik bir yöntem önerilir. Yukarıda aktardığım pasajın devamında da Sokrates "neden" arayışı açısından nesnelerin kendilikleri (auto) itibariyle idealarından bahsederek, bir bakıma duyumsanabilir şeyler ile onların ideaları arasında hakiki bir söylem/teori geliştirmenin yolunu açmaktadır. Bu yöntem de Sokrates'in neden arayışında "ikinci yolculuk" olarak tanıtılır. ${ }^{13}$

Sokrates'in Ön-Sokratik doğa araştırmalarından etkilendiği birinci yolculuğun temel karakteristiği, nedeni, salt doğanın (physis) içinde arayan fizik merkezli nedensellik anlayışıdır. Bu araştırmanın yetersizliği, oluşun dışında (ya da ondan başka) bir gerçeklik alanını incelemeye dahil etmemesidir. Bu bakımdan Sokrates'in, Anaksagoras'ın “nous” (akıl) kavramından etkilenmesi sıradan değildir. Genç Sokrates doğal nedenselliğin kendisine göre gerçekleştiği ve çoklu dünyayı bir arada tutup onları birbirine bağlayan şeyin onlardan biri olmayan "en iyi" niteliğiyle "nous" olabileceğini düşünmüş olabilir. Ancak Anaksagoras'ın, doğal nedensellik itibariyle ön plana çıkan nous'unun da, Sokrates'in nous'una uymaması onu ikinci bir yolculuğa sevk eder.

11 Murphy, "The $\Delta \varepsilon v \dot{\tau \varepsilon \rho \circ \varsigma} \Pi \lambda$ ov $\varsigma$ in the Phaedo" The Classical Quarterly 30/2 (1936), 45.

12 J. T. Bedu-Addo, "The Role of the Hypothetical Method in the Phaedo", Phronesis 24/2 (1979), 113.

13 Phaidon'da aktarılan ikinci yol(culuk) olarak hipotez yöntemi ile Devlet diyaloğunda (VI. Kitap) çizgi benzetmesi üzerinden sunulan diyalektik yöntem arasındaki benzerlikler hakkında ayrıntılı bir okuma için bkz. Miriam Newton Byrd, “Dialectic and Plato's Method of Hypothesis”, Apeiron 40/2 (2007), 141-158. 
Antik Yunan'da deuteros plous'un, gemicilikle ilgili teknik bir kullanımı olduğu da söylenmektedir. Buna göre deuteros plous, deniz yolculuğu esnasında rüzgarın durması durumunda, gemicilerin, kalan yolu küreklerle tamamlamasına referansla kullanılan bir terimdir. ${ }^{14}$ Bu bağlamda Sokrates' in yeniden ikinci yolculuğa çıkması, doğal etkilerin eksik olduğu bir ortam itibariyle rüzgarın olmadığı bir durumda, kalan yolu beşeri bir çabayla tamamlamak içindir. Başka bir deyişle Sokrates gerçek nedeni artık doğada değil, logoi itibariyle kendisinde aramaya başlar. Buna rağmen bazı araştırmacılara göre Sokrates’in ikinci yolculuğu, birincisinden "daha güvenli" değildir. Zira bir amaca ulaşmak için en güvenli yol daima birincisidir. İkinci yol, birincinin olmadığı bir durumda alternatif olarak görülür ve birinciye göre "ikinci en iyi yol”dur. $\mathrm{Bu}$ bakış açısıyla iki alternatiften birini diğerine tercih etmenin gerekçesi, önceki seçeneğin daha iyi olduğu varsayımıdır. ${ }^{15}$

Bu metaforu bir amaca ulaşmak için belirlenen planlar üzerinden düşünelim. Söz gelimi A ile B planlarının yapıldığı bir çalışmada birincinin işlemediğini, böylece ikinci planın devreye girdiğini varsayalım. Böyle bir durumda B planı ilkine göre daha az mı güvenlidir? Deniz yolculuğu metaforu üzerinden söylenecek olursa, rüzgarın olmadığı bir yelkenlide, yola küreklerle devam etmek ilkine göre neden güvensiz olarak görülür?

Sokrates' in ulaşmaya çalıştığı hedef doğanın ve oluşun içinde doğrudan görünüşe çıkmayan metafizik içeriğiyle "en iyi”" dir. Bu açıdan mükemmel olan amaca/hedefe ulaştıran yol, Sokrates için en sağlam ve güvenli olanıdır. Üstelik Sokratik bilgelik ve Platon ontolojisi açısından da diyalektik olarak "sonradan gelen” bir şeyin "önceki” ne göre değersiz ya da güvensiz olduğunu iddia etmek pek mümkün değildir. Ben bu bağlamda metafora fazla yüklenmenin hatalı olduğu ve "metafor" un filolojik çağrışımlarından ${ }^{16}$ hareketle de kendisi aracılığıyla taşınanları batırma tehlikesi arz ettiği kanaatindeyim. Dolayısıyla Sokrates'in ikinci yolculuğunun, birincisinden daha güvenli olmadığını iddia edenlerin bu görüşlerinin, metnin iç bütünlüğü açısından tutarlı olduğunu düşünmüyorum. Bu bakımdan Sokrates’ in kendi logoi una dayalı ikinci yolu (yöntemi), hakiki bilginin ve gerçeğin keşfedilmesi açısından ilkine göre daha sağlam ve güvenilirdir. Ayrıca bu metafor üzerinden, oluş ve bozuluşun hakiki nedenini arayan genç Sokrates'in, gerek ÖnSokratik doğa biliminin gerekse Anaksagoras'in nous'unun yetersizliklerini görmesi sonrasında, eşyanın hakikatini kendisindeki imgesel karşılıklar açısından aradığı unutulmamalıdır.

Ön-Sokratik birinci yolculuktan Sokratik ikinciye doğru seyrederken, doğal şeylerden ideallere doğru diyalektik bir geçiş göze çarpar. Amaca uygunluk açısından da Sokrates’in ikinci yolculuğunun ilkine göre daha güvenli olması gerekir. Bu açıdan ikinci yolculuğa, doğa

14 Donald L. Ross, "The Deuteros Plous, Simmias' Speech, and Socrates' Answer to Cebes in Plato's Phaedo", Hermes 110/1 (1982), 20; Rosamond Kent Sprague, “Socrates' Safest Answer: Phaedo 100D”, Hermes 96/4 (1968), 634; Bernard Freydberg, "Sallis on Deuteros Plous: The Philosopher as Voyager", The Journal of Speculative Philosophy $27 /$ 2 (2013), 200.

15 Bu konudaki farklı görüşler için bkz. Tonguç Seferoğlu, "A Metaphilosophical Reading of Plato’s Phaedo”, (Doktora tezi, King's College London, 2018), 127-133.

16 Yunanca "öte” anlamında gelen “meta” sözcüğü ile nakletmek, taşımak ya da geçmek anlamında gelen "phero" -ki bu terim dilimize feribot olarak geçmiştir- fiilininin bileşiminden oluşan "metafor” sözcüğü, karşıya/öte tarafa geçme, taşıma ve nakletme gibi anlamlara gelmektedir. 
araştırmalarındaki eksiklikleri ve neden arayışı itibariyle yetersizlikleri gören Ön-Sokratik Sokrates'in metafizik arayışı da denilebilir. Gençlik yıllarında doğa araştırmalarının yanılgı ve hatalarını fark eden Ön-Sokratik Sokrates, ikinci yolculuğunda, varolan tek tek şeylerin gerçek nedenini "logoi" da aramaya başlar. Böylece birinci yolculuktaki eksiklikleri fark etmeden ikinci yolculuğa çıkılamayacağı da gözler önüne serilmiş olur. Dolayısıyla ruh ve kendilik (auto) gibi metafizik bir meselede oluşun döngüselliğinden çıkmakta zorlanan ve şüphelerinde debelenen Kebes'e, Sokrates, kendi entelektüel otobiyografisi üzerinden ölümsüzlüğün yaşamda kazanılan bir deneyim olduğunu ve öz-farkındalık gerektirdiğini göstermek ister. Zira Kebes her ne kadar ideaların ezeli varlığını ve ruhun bedene göre dağılmaz/basit olduğunu kabul etse de, ölümsüzlüğün bu dünyada bilinemeyeceğini savunmaktadır. Bu noktada Kebes’in, ruhun dağılmaz ve bölünmezliği (yalınlığı) ile ölümsüzlüğü arasında gördüğü gerilimi Sokrates kendi yaşam deneyimi üzerinden "kendilik idrakine" çekerek çözmek ister. Başka bir deyişle diyalogda doğrudan dile getirilmese de "ruhun dağılmaz ve bölünmez oluşu, ilkesel olarak birinin ölümsüzlügünü garanti etmez” tarzında anlaşılabilecek iddia, Sokrates' in otobiyografisi üzerinden kendi yaşam diyalektiğinde yerini bulur. Bu anlamda Sokrates, ruhun ölümsüzlügünün idraki için ölüm pratiği ve ruhsal arınma deneyimlerinin bu dünyada yaşanması gerektiğini kendi tecrübesi üzerinden sunar. Bu yönüyle sadece düşünme değil, ama "bir yaşama biçimi olarak felsefe" den bahsedilmedikçe Sokrates için ölümsüzlüğün idrak edilmesi mümkün değildir. Zaten bu iddia ruhun aklen kanıtlanmasıyla bağlantılı olarak söylenen ve Antik Yunan dini inanışlarıyla örtüşen savla da paralellik arz eder. $\mathrm{O}$ da ruhun ölümsüzlügünü bu dünyada yaşayarak edinmeyen ve gündelik pratik kaygılardan uzaklaşmayan kişiler için ölümsüzlük diye bir şeyin söz konusu olamayacağı savıdır. Bu itibarla Sokratik yaşamda bilgelik bu tarz bir mücadelenin konusu olup, salt muhakeme mantığına indirgenmeyecek bir yaşam tecrübesini gerektirir. Bu tecrübe birinci yolculuktan ikinciye yeniden çıkma cesaretini gösteren Sokrates’ in ikinci yolculuğunda kazanılır.

Ön-Sokratik Sokrates’in birinci yolculuğunun doğallığı ile değişim dünyasının doğasından logoi yoluyla kendisine çekilen Sokrates'in ikinci yolculuğu bu nedenle birbirinden çok farklıdır. Kebes'in iddiası karşısında Sokrates'in, diyaloğun bu yerinde, kendi yaşam deneyimini devreye sokmasında ön plana çıkan, hataya düşme ve bunu fark edip yoluna yeniden devam vurgusu ise manidardır. Burada doğaya logoi aracılığıyla yeniden dönme, doğanın yine logoi aracılı̆̆ıyla dönüşümü gibidir. ${ }^{17}$ Aslında Sokrates’in bu anlatısında başlangıcın doğallığ ontolojisinin genel karakteriyle son derece uyumludur. Mağara benzetmesi üzerinden söylenecek olursa, kişi, kendisini doğal olarak doğanın içinde zincirlenmiş olarak bulur. Üstelik doğal olanın söylem (logos) tarafından yakalanması da zordur. Sokrates bir bakıma bu zorluğa katlanmak ve hakikat yolunun yolcusu olmak gerektiğini ifade eder.

Sokrates'in birinci ve ikinci yolculuğa dair konuşmasını, salt doğal nedensellik üzerinden ruhun ölümsüzlüğünü kavramaya çalışan Kebes’e hitaben yaptığı gözlerden kaçmamalıdır. Bu açıdan doğal olanın sürekliliği ve değişkenliğinde gerçek nedenin ancak kalıcı bir varlıkla irtibat üzerinden söylem aracılığıyla akıl tarafından (noèsei meta logou) kavranabileceği gerçeği Sokrates

17 Sallis, Being and Logos: Reading the Platonic Dialogues, 47. 
tarafından ön plana atılır. Böylece kişi sadece deuteros plous ile (rüzgâr olmadan kürek çekerek) şeylerin değişmez varlığına yaklaşır. Bu deneyim de duyumsanabilir dünyada tezahür eden şeylerden uzaklaşmayı ve doğadan söyleme yönelerek varlığın hakikatini görmek (skopein) için logoi’a başvurmayı gerektirir. Dolayısıyla ruhun ölümsüzlüğü bağlamında doğa biliminden logoi aracılığıyla idealara yönelen Sokratik yolculuk şu şekilde yorumlanabilir: Ölümsüzlügün hakiki idraki, ruhun, ölümlü şeylerden kendisine dönmesiyle mümkündür. Başka bir ifadeyle ruh ve ölümsüzlük, ruhun kendisine dönüp, kendisini araştırıncaya ve bütünü kavramayı deneyip başarısızlığa uğrayıncaya kadar fark edebileceği bir mesele değildir. Bu anlamda logoi, nesneler ile idealar arasında birer sûret olarak görülür. Böylece nesnelerin bendeki karşıllı̆ı olarak sûretler bana varlığın kendilerini açacak ve şeylerin hakiki nedenlerini kavramama yardımcı olacaktır.

\title{
3. Bir Hypothesis olarak Logos
}

Sokrates Ön-Sokratik doğa araştırmasından farklı olarak dışsal nesnelerle ilişkisini logoi aracılığıyla kurması gerektiğini ifade ettikten sonra sözlerini şu şekilde sürdürür:

\begin{abstract}
Şimdi üzerinde çalıştığım nedenin mahiyetini (eidos) açıklamaya çalışacağım sana, sürekli üzerinde konuştuğumuz konuya yeniden döneceğim ve oradan başlayacağım. Kendinde güzel, kendinde iyi ve kendinde büyük ve bunun gibi konularda varlıkların olduğunu varsayıyorum (100b).
\end{abstract}

Bu pasajın son cümlesinden hareketle Sokrates/Platon'da ideaların, modern içeriğiyle "bilimsel bir hipotez" (varsayım) olarak ele alınamayacağı aşikardır. Bununla birlikte Sokrates için "her bir durumda logoi a dayanma” (100a 4: hypothemenos logon) ifadesinin bu pasajla birlikte açılması gerekmektedir.

Platon ontolojisinde hypothesis ile modern dönemde bilimsel hipotezin birbirine benzerliği yanında, tamamıyla aynı şey olmadığını ifade etmek gerekir. Devlet diyaloğunun VI. kitabının sonunda resmedilen bölünmüş çizgi benzetmesinde, kavranılır (noeton) bölmenin alt kısmında yer alan muhakeme (dianoia) faaliyeti, köken/ilke (arkhé) yerine, kendisine zemin aldığ şeylerden (hypothéseis) hareketle araştırmasına yönelir. Bu açıdan Sokrates için varlık (ousia) düzlemine (thesis) referansla kullanılan ideaların birer varsayım olarak anlaşılması pek mümkün görünmemektedir. Aksine Sokrates'e göre hypothesis'in, kökene yönelen bir yükselmenin ya da sıçramanın alt-zemini (hypo-thesis'i) olarak kabul edilmesi gerekir. Böylelikle muhakemeye dayalı zeminin aşılması (bypothéseis'in olumsuzlanması) yoluyla anhypotheton tecrübesi yaşanabilir ve araştırılan konuda köken/ilke (arkhé) kavranabilir. ${ }^{18}$ Dolayısıyla ilgili bağlam ve yukarıdaki pasajdan hareketle Sokrates için kendinde ideaların değil, onlara ilişkin logoìun, birer hypothesis olarak kabul edildiğini ileri sürüyorum. Başka bir deyişle ideaların değil, onlara ilişkin söylemlerin geçici olarak doğru olduğu varsayılır.

18 Oğuz Haşlakoğlu, Platon Düşüncesinde Tekhné: Sanat ve Felsefenin Ortak Kökeni Üzerine Bir İnceleme (İstanbul:

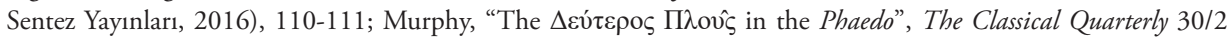
(1936), 46; Byrd, "Dialectic and Plato's Method of Hypothesis", Apeiron 40/2 (2007), 156. 
Bu noktada şu soru sorulabilir: Sokrates'e göre Ön-Sokratik doğa araştırmalarının logik bir gayesi yok mudur? Sokrates' in iddia ettiği gibi, Ön-Sokratikler, araştırmalarında yalnızca duyularını mı kullanmışlardır? Sokrates’te logoi "teori/ler" olarak anlaşıldığında, birinci yol/culuğun doğası gereği, bilimsel teorilerden bahsedilemez mi? Aslında bu konuda -diyalogda çok fazla ön plana çıkmamakla birlikte- Sokrates'in, Ön-Sokratiklerin logoi’a sahip oldukları gerçeğinin farkında olduğu iddia edilebilir. Ancak burada Sokrates'in Ön-Sokratiklerle ilgili sorunu, bu türden araştırmalarda logoi un, yukarıda da ifade ettiğim gibi, değişmez mahiyetler itibariyle idealara referansla birer hypothesis olarak kabul edilmemiş olmasıdır. Bu bağlamda Platon muhtemelen Ön-Sokratiklerin, logoi u, kesin ve mutlak içerikle bilgi nesnesi olarak kabul ettiklerini, dolayısıyla muhatabını hakikat esasında doğru bilgiye ulaşmaya götürebilecek olan söylem sanatından (logon tekhne) mahrum olduklarını düşünür. ${ }^{19}$ Nitekim Ön-Sokratikler, logoi larının ötesine geçmeye gayret etmezler ve onlarda sabit kalırlar. Bu nedenle Ön-Sokratikler, kanıtlamalarının gerçek ve teorik açıklamalarını (logoi) yapamazlar. Halbuki Platon ontolojisinde bu araştırmaların uygun bir biçimde bilgiye erişim imkanı yoktur. Zira yalnızca filozof, hypothéseis'i "aşıp" anhypotheton tecrübesini yaşayarak, tüm idealar gibi İyi’nin kendisine ve ruhun ölümsüzlüğüne vakıf olabilir.

Hypothesis, varlık esasında aşkın bir düzlemin (thesis) kabulü bakımından, diyalogda geçen "kafa farkı" ve "toplama-çıkarma" sorunlarıyla da irtibatlıdır. Ön-Sokratiklerden kopuşuyla bağlantılı olarak Sokrates, kısa birinin yanında uzun görünen bir adamın sadece kafa farkıyla uzun olduğunu düşünmenin yeterli olmadığını ifade eder. Burada dile getirilen sorun, kısa boylu birinin uzun boylu birinden kafa farkıyla kısa olduğunu -ya da aynı nedenle tersini- düşünmekle ilgilidir (96d-e). Bu noktada iki karşıt için de aynı şey (kafa farkı) neden olarak görülür. Halbuki Sokrates-Simmias-Phaidon üzerinden verilen sonraki örnekte uzun olan birinin "uzunluk" ideası, kısa olan birinin de "kısalık" ideasından pay alması nedeniyle öyle oldukları kabul edilir (102be). İkinci sorun ise bire bir eklendiğinde iki elde edilirken, biri ikiye böldüğümüzde yine iki parçanın elde edilmesiyle ilgilidir (97a-b). Burada da iki farklı neden (toplama ve bölme) aynı şeye (ikiliğe) yol açmaktadır. Halbuki sonraki konuşmada Sokrates tıpkı kafa farkı sorununda olduğu gibi, bunun da pay alma teorisi (logos) ile çözülebileceğini savunur (104a-e). Tartışmanın bağlamıla ilgili söylenecek olursa, oluşun döngüselliğinde doğal olanın nedensel açıklaması, söz konusu bu döngü içerisinde akışa tabi herhangi bir unsura indirgenemez. Ön-Sokratiklerin, algı dünyasını aşamayan açıklamalarındaki sorun da Sokrates'e göre budur. Bu sorunu ve ona yönelik Sokratik yaklaşımı Kebes'in itirazına uyarladığımızda, ruhun ölümsüzlüğünü, salt oluş ve bozuluş dünyasının sınırları içerisinde anlamaya ve kanıtlamaya çalışmanın yetersizliği gözler önüne serilir. Böylece Sokrates şeylerin hakiki gerçekliği gibi ruhun da ölümsüz mahiyetini araştıran birisinin, aldanış dünyasının (doksa) sınırlarını görmesi (noesis) için bu sınırların dışına çıkması gerektiğini savunur.

Ön-Sokratik bir aşamadan geçerek ama ondan farklı bir biçimde Sokrates, değişmez ve sabit ideaların kendinde gerçekliğinin zorunluluğunu, değişebilir dünyanın nedensel açıklanması için güvenilir bir yol olarak kabul eder. Böylece Sokratik açıklamada güzel görünen tek tek şeylerin güzel olmasının nedeni güzelin kendisinden pay almasıdır (metheksis). Dolayısıyla Sokrates için oluş dünyasında değişime tabi hiçbir şeyin nedeni onlardan biri olamaz. Aslında 
Platon ontolojisinde "ikilik" olarak ön plana çıkartılmak istenen düzlemsel ayrım da tam olarak budur. Burada fiziksel çoklunun kendisine göre gerçekleştiği nedenin, o çokludan herhangi biri olamayacağı söylenmektedir. Bunun için de iki düzlem arasında bir ayrımın önemine işaret edilir. Böylelikle Sokratik bilgelikte "nedenin kendisi ile o olmasaydı nedenin de neden olamayacağ şeyi birbirinden ayırt etme" nin (diairesis: 99b) ontik anlamda ne kadar önemli olduğu belirtilmiş olmaktadır. Birinci yolculukta Sokrates’i tatmin etmeyen şey, doğanın kendisine göre değiştiği ilkenin, doğanın içinde aranmasıdır.

Sokrates' in söz konusu bu farkındalığı kendi otobiyografisi açısından sunması da manidardır. Dolayısıyla iki düzlem arasındaki farkın "fark edilmesi" ile başlayan yolculuk, fizikle başlayan ama ondaki yetersizlikleri diyalektik bir tarzda aşmakla ilgili metafizik bir çabayı gerektirir. Böylece kendilik/ben tecrübesi üzerinden Sokrates’in, fiziksel dünyaya ilişkin açıklamalardaki yetersizliği fark edip onda bulunmayan yetkin ve mükemmel olanı arayışı, ona fizikten metafiziğe geçişin yollarını açmıştır. Ancak Platon tarafından ideaların birer neden olarak kabul edildiği ve hypothesis olarak logos'un da değişmez idealara erişim imkanı açısından ortaya atıldığı dikkatlerden kaçmamalıdır.

Sokrates, ikinci yolculuk olarak betimlediği yolun, tikellerin idealara katılımı ya da onlardan pay alması bakımından en sağlam ve güvenilir açıklama olduğunu belirtir. Bu nedenle oluşun nedensel açıklamasında katılım ve iştirak açısından logos'un bir hypothesis olarak kabul edilmesi gerekir. Hypothesis belirlendikten sonra da ona uyan (symphonei) doğru, uymayan ise yanlış olarak kabul edilecektir. Bu noktada Sokrates 1) en güçlü logoì varsaymak, 11) ona uyan her şeyi doğru, uymayanı da yanlış olarak belirlemek ister (100a). Bir şeyin hipotez olarak kabul edilmesindeki amaç, her ne kadar onun geçiciliğini ve henüz bilinmediğini belirtmekse de, buradaki geçicilik ve belirsizliğin, hakikatin inkarı olarak anlaşılmaması gerekir. Başka bir deyişle hipotezin geçiciliği itibariyle hakikatin söylemsel olarak mutlak ve kesinlik arz etmeyeceği fikri hakikate aykırı değildir. Aksine herhangi bir konuda hipotetik açıklamanın olası doğruluğu ve görece belirsizliği, aslen aşkın ve sabit bir hakikatin varlığının kabul edilmesini zorunlu kılar. Bu anlamda Platon felsefesi aşırı şüphecilik ile dogmatizm arası bir konumda yer alır. ${ }^{20}$

Bir hipotezi hipotez yapan şey aynı zamanda hesaba (logos) tabi olmasıdır. Bu durum hipotezin asla bir bilgi nesnesi olamayacağı ya da diyalektikçinin bunu bilemeyeceği anlamına gelmez. Herhangi bir konuda araştırma yapan biri, anlaşılabilir şekilde bir argümandaki en güvenli hipotezi seçebilir. Bununla birlikte bu hipotezin geçici olması bizi Platon'da ideaların geçici olduğu gibi bir görüşe sevk etmemelidir. Platon ontolojisinde "idealar vardır”. Ancak varlık düzleminin (thesis) muhakemeye (dianoia) dayalı teorik açıklamasında (logos) geçicilik itibariyle birtakım değişiklikler olabilir. Bununla birlikte hipotezler özenle seçilmişse, kesin sonuçlara ve hiç de geçici olmayan sonuçlara yol açabilir. Bu nedenle Phaidon'da varsayımsal (hipotetik) yöntem "neden olarak idealar" açısından açıklama elde etmek için kullanılır ve bu durum, şeylerin nedenleri olan ideaların var olduğu gerçeğini değiştirmez. ${ }^{21}$

20 Seferoğlu, "A Metaphilosophical Reading of Plato's Phaedo", 153.

21 Lynn E. Rose, “The Deuteros Plous in Plato's Phaedo", The Monist 50/3 (1966), 471. 
Diyalogda geçen hipoteze "uyma” (symphōnéó) fiili, değişmez nedenlere uygunluk bakımından tutarlılık ya da zorunluluk bağlamında kullanılsa da, terimin "müzikal" (senfoni/k) içeriği dikkate alındığında ilginç bazı çıkarımlar yapılabilir. Bu yazının sınırlarını aşmakla birlikte ilgili bağlam ve terimin müzikal çağrışımıyla birlikte şunlar söylenebilir: Birbiriyle uyumlu olmayan herhangi iki nota (söz gelimi Re ve Fa notaları) müzikal bir eserin bütünlügü içerisinde senfonik bir birlik oluşturur. Burada müzikal bir eserde notaların belirli aralıklarla ilişkilendirildiğinde birlik oluşturma biçimi ile teorik varsayımların birbiriyle ilişkisi itibariyle birliği arasında bir benzerlik vardır. Bir makam dizisi veya herhangi bir karar sesiyle ilişki içerisinde olmayan iki farklı notanın kendi aralarında uyumlu olması gerekmez. İki farklı nota müzikal birliğini senfonik bütünlük içerisinde kazanır ve bu benzetme teorik açıklamalar için de geçerlidir. Üstelik bu terim hakikate nispetle teorilerin geçiciliği ve belirsizliğiyle de uyumludur. Aynı aralık ve perde dizilimi içerisinde birbirinden farklı müzikal eserlerin bestelenmesindeki belirsizlik de buna örnektir. Buna "müzikal belirsizlik" adı verilebilir. Dolayısıyla birbiriyle ilişkisiz birçok notayı birbiriyle uyumlu bir tarzda senfonik olarak bir araya getirmenin belirsizliği ile hakikate uygun (senfonik) varsayımların görece belirsizliği arasında bir benzerlik sözkonusudur. Başka bir deyişle karar sesiyle ilişkisinin sabitliğine rağmen herhangi bir makamda bestelenen eserin birbiriyle aynı olmaması itibariyle belirsizliği, varsayımsal açıklamanın senfonik doğasıyla uyumludur. Bu bağlamda, Sokrates, kendi içinde senfonik bir teori oluşturmak ve orada bulunan dostlarından da kendi ölümünden sonra bu arayışın peşinde olmaları için çaba göstermelerini ister. Sokrates bu görüş ve temennisini şöyle dile getirir:

Size güvenilir gelse de onları [varsayımları] titiz bir şekilde incelemek gerek. Onlar hakkında yeterli uzlaşma sağlarsanız bu savı, bir insanın götürebileceği en yüksek noktaya taşırsınız diye düşünüyorum (107b, italik bana ait).

\section{Sonuç}

Phaidon diyaloğunda aktarıldığı kadarıyla Sokrates’ in, gerçek nedeni doğanın içinde aradığı "Ön-Sokratik" bir dönemi vardır. Bu da felsefe tarihinde aktarılan tarzda 'Ön-Sokratik' ve 'Sokratik' arasındaki ayrımın keskin olmadığını ve Sokrates özelinde fiziksel olan ile ona aşkın metafizik arayış arasında diyalektik bir geçişin olduğunu göstermektedir. Buna göre doğadaki nedensel arayışın eksikliğini fark eden Sokrates, ikinci bir yolculuğa çıkarak, doğal süreci kendisine göre açıklayabileceği hakiki bir nedenin peşine düşer. Bu bağlamda birinci yolculuktan ikinciye diyalektik bir geçiş olduğunu düşünüyorum. Dolayısıyla Ön-Sokratik araştırmanın eksikliklerini fark eden Sokrates' in ikinci yolculuğa çıkışı diyalektik bir hareketi gerektirmektedir.

Burada önemli olan konu bu tartışmanın ruhun ölümsüzlüğüyle ilgili olarak ortaya atılmasıdır. Böylece doğa araştırmalarının imkanı, bitimli olana değil, ölümsüz bir töze dayandırıldığında, ruhun ölümsüzlüğünün kabul edilmesi itibariyle idealardan bahsetmeyi, dolayısıyla duyumsanabilir şeylerin hakiki nedenine/nedenselliğine vakıf olmayı gerektirmektedir. Ancak Sokrates'in otobiyografisini paylaşmasındaki gerekçenin, idealar ya da ruhun ölümsüzlügünün idraki için gerekli olan varsayımsal yöntemin aşılması olduğu da unutulmamalıdır. Başka bir deyişle 
Sokrates ideaların ve ruhun ölümsüzlüğünün bilgisine ulaşma yolunda ilerlemesine rehberlik etmesi için gerekli duyu deneyimini varsayar. Bununla birlikte fiziksel olandan metafiziğe geçişin imkanı gibi, oluştan varlık düzlemine geçmek de ilkinin aşılması dolayımıyla mümkündür. Sokrates için aşkın bir meseleye salt bilimsel (fiziksel) açıdan bakan Kebes gibilerinin sorunu da bu olabilir. Bir bakıma Sokrates'in Kebes'e söylediği şudur: Logoi öldürülmeden/tüketilmeden ya da geçici olmaları bakımından onların ölümlü oldukları fark edilmeden, saf olarak ölümsüzlügün bu dünyada idrak edilmesi mümkün değildir. Sonuç olarak, bitimli olanlara yönelik farkındalık, ölümsüzlüğe ilişkin idrakin ön koşuludur. Bu farkındalık da fizikten metafiziğe diyalektik geçişi temin eder. Bu açıdan Sokratik bilgelikte ölümsüzlük, ancak ölüm pratiği ve arınma gibi tecrübeler yoluyla fiili olarak idrak edilebilir. Ruh gibi aşkın ve metafizik bir meselede şeylerin kendilerini bilmek de ancak kişinin kendini idraki ile mümkündür.

Hakem Değerlendirmesi: Dış bağımsız.

Çıkar Çatışması: Yazar çkar çatış,ması bildirmemiștir.

Finansal Destek: Yazar bu çalışma için finansal destek almadığını beyan etmiştir.

Peer-review: Externally peer-reviewed.

Conflict of Interest: The author has no conflict of interest to declare.

Grant Support: The author declared that this study has received no financial support.

\section{Kaynaklar / References}

Bedu-Addo, J. T. “The Role of the Hypothetical Method in the Phaedo". Phronesis 24/2 (1979): 111-132.

Byrd, Miriam Newton. "Dialectic and Plato’s Method of Hypothesis”, Apeiron 40/2 (2007): 141-158.

Freydberg, Bernard. "Sallis on Deuteros Plous: The Philosopher as Voyager". The Journal of Speculative Philosophy 27/ 2 (2013): 199-207.

Haşlakoğlu, Oğuz. Platon Düşüncesinde Tekhné: Sanat ve Felsefenin Ortak Kökeni Üzerine Bir İnceleme. İstanbul: Sentez Yayınları, 2016.

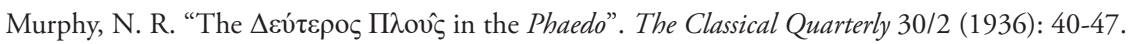

Pakaluk, Michael. “The Ultimate Final Argument”. The Review of Metaphysics 63/3 (2010): 643-677.

Platon. Euthyphro, Apology, Crito, Phaedo, Phaedrus. Çeviren H. N. Fowler. Cambridge: Harvard University Press, 2005.

Platon. Phaidon. Çeviren Nazile Kalaycı. İstanbul: Pharmakon, 2020.

Platon. Devlet. Çeviren. Hüseyin Demirhan. İstanbul: Sosyal Yayınları, 2002.

Rose, Lynn E. “The Deuteros Plous in Plato's Phaedo". The Monist 50/3, (1966): 464-473.

Ross, David. Plato's Theory of Ideas. Oxford: Clarendon Press, 1951.

Ross, Donald L. “The Deuteros Plous, Simmias' Speech, and Socrates' Answer to Cebes in Plato's Phaedo". Hermes 110/1 (1982): 19-25.

Sallis, John. Being and Logos: Reading the Platonic Dialogues. Indianapolis: Indiana University Press, 1996.

Seferoğlu, Tonguç. “A Metaphilosophical Reading of Plato's Phaedo.” Doktora tezi, King's College London, 2018.

Sprague, Rosamond Kent. “Socrates' Safest Answer: Phaedo 100D”. Hermes 96/4 (1968): 632-635. 
